\title{
O EFEITO DO BIOGÁS NA TEMPERATURA DE CHAMA, QUANDO USADO COMO COMBUSTÍVEL AUXILIAR*
}

\section{Resumo}

\author{
Júnio Augusto Rodrigues Pasqual ${ }^{1}$ \\ Kerlly Oliveira Calixto ${ }^{2}$ \\ Máximo Eleotério Martins ${ }^{3}$ \\ Paulo Santos Assis ${ }^{4}$
}

No processo de produção de gusa são frequentes as pesquisas em busca de meios de redução dos custos do produto final, além de adequações do processo à escassez de matéria-prima e tudo isso com o intuito final de garantir a lucratividade do setor. A preocupação com os impactos ambientais do processo também é assunto frequentemente levantado por profissionais da área devido à sua igualmente grande importância. Através da injeção de materiais pulverizados e gás pelas ventaneiras de um reator é possível conseguir economia de gastos com adição de carvão de topo. Por esse motivo e também visando à redução dos malefícios causados pela liberação de gases diretamente na atmosfera que surgiu a ideia da injeção de biogás pelas ventaneiras. Assim é possível evitar a liberação de $\mathrm{CH}_{4}$ que é altamente prejudicial à vida no planeta, além de reduzir o consumo de carvão de topo no Alto-Forno.Este trabalho discute a variação da Temperatura de Chama frente o efeito da utilização de biogás em Altos-Fornos, bem como o potencial energético desse gás tendo em vista a abundância de fontes de metano provenientes do setor bovino e suíno no Brasil.

Palavras-chave: Biogás; Alto forno; Injeção.

\section{THE BIOGAS EFFECT IN FLAME TEMPERATURE WHEN USED AS FUEL} AUXILIARY

\section{Abstract}

In the production process of pig iron is common the researches seeking new ways to reduce the final product costs, as well as adjustments of the process like the shortage of raw material and with the final aim of guaranteeing the sector's profitability. Professionals due their big importance also discuss the concern about the environmental impacts of the process. Through the injecting of puveralized materials and auxiliary material by the tuyeres of a reactor is possible to save cost with added of top coal.For this reason and in order to reduce the harm caused by the release of gases directly into the atmosphere came the idea of biogas injection by the tuyeres. Thus is possible to avoid the release of $\mathrm{CH}_{4}$ that is highly damaging for life on the planet, while reducing top coal consumption in the blast furnace. This paper discusses the variation of the flame temperature front the effect of the use of biogas into blast furnaces and the potential of biogas comparing to the abundance of methane sources from bovine and swine sector in Brazil.

Keywords: Biogas blast furnace; Injection.

\footnotetext{
Estudante de Graduação, Engenharia Metalúrgica, UFOP, Membro da ABM, MG, Brasil. Mestranda em Engenharia de Materiais, REDEMAT / UFOP, Membro da ABM MG, Brasil. Doutorando em Engenharia de Materiais, REDEMAT / UFOP, Ouro Preto, MG, Brasil.

Doutor em Engenharia Metalúrgica, Professor, Departamento de Engenharia

Metalúrgica, UFOP/Redemat. Membro da ABM, Ouro Preto, MG, Brasil.
} 


\section{INTRODUÇÃO}

O aumento da população mundial leva à elevação das demandas, que por sua vez leva à elevação da quantidade de indústrias, com destaque para o período seguinte à revolução industrial, quando esse número cresceu consideravelmente. Os países desenvolvidos necessitam manter seu patamar de consumo, além de atender ao mercado externo também faminto por produtos e serviços. Porém, juntamente com essa grande quantidade de indústrias, vem a grande quantidade de poluentes gerados durante o processo produtivo. A liderança dos países com maior poder econômico está atrelada à responsabilidade pela emissão da maior parcela aos gases danosos ao meio ambiente. Assim como o volume de gases do efeito estufa (GHG - Greenhouse Gas) lançados na atmosfera é cada vez maior, as preocupações com as consequências dessas emissões também cresce a cada dia. Crescem cada vez mais os estudos relacionados às formas de reduzir os prejuízos causados por esses gases assim como reduzir a quantidade de gases jogados na atmosfera.

Várias são as alternativas para redução das emissões de GHG. Uma solução mais recente para o problema em questão é a utilização de material de fontes orgânicas e que possam ser reciclados, que são comumente chamados de biomassa. Biomassa é um material cujos resíduos podem ser reaproveitados, além do mais, ela pode ser transformada em vários tipos de energia como térmica e elétrica.

A preocupação com as questões ambientais fez com que as tecnologias de desenvolvimento no meio industrial voltassem suas frentes de pesquisa também para esse campo buscando meios de reduzir ou eliminar os efeitos deletérios ao meio ambiente, provenientes de práticas inerentes ao processo produtivo.

Uma das técnicas mais difundidas em indústrias voltadas para a produção de aço é a injeção de combustíveis pelas ventaneiras dos Altos-Fornos. Essa técnica é vantajosa não só com relação à questão ambiental, mas também por ser de importante valia levando em consideração a escassez de matérias primas de qualidade para serem carregadas no topo do forno e também devido à alta competitividade característica do setor siderúrgico [1].

Juntamente com a injeção de materiais pulverizados pelas ventaneiras dos Altos Fornos, é feita também a injeção de gases combustíveis. Atualmente ogas mais utilizado para injeção em Altos-Fornos é o gás natural e, atualmente tem se feito estudos com um novo gás para combustível auxiliar, o biogás.

A injeção de gás natural juntamente com o combustível pulverizado resulta em redução do consumo de coque no topo, já que parte do carbono é adicionado pelas ventaneiras (levando à redução direta dos custos de produção de gusa), tem-se também a redução do volume de escória e temperatura de chama que é resultado do efeito refrigerante do gás natural e do carvão pulverizado [2].

O gás natural em questão é composto de metano $\left(\mathrm{CH}_{4}\right)$ em sua maioria. A porcentagem $\mathrm{CH}_{4}$ é superior a $90 \%$. O metano é um gás de grande impacto na atmosfera devido à sua elevada capacidade de absorção de radiação ultravioleta por molécula, chegando a um poder de absorção 23 vezes maior que o do $\mathrm{CO}_{2}$ [3].

A tabela 1 representa a composição química de um biogás produzido por uma concessionária. É possível perceber que o biogás tem de mais de cinquenta por cento de metano, porém a composição pode variar dependendo do processo de sua obtenção. 
Tabela 1: Composição do Biogás [5]

\begin{tabular}{ccc}
\hline Gás & \% Volume & FórmulaQuímica \\
\hline \hline Metano & $55-75$ & $\mathrm{CH}_{4}$ \\
\hline $\begin{array}{c}\text { Dióxido de } \\
\text { Carbono }\end{array}$ & $25-45$ & $\mathrm{CO}_{2}$ \\
Nitrogênio & $0-3$ & $\mathrm{~N}_{2}$ \\
Hidrogênio & $0-2$ & $\mathrm{H}_{2}$ \\
Oxigênio & $0-0.1$ & $\mathrm{O}_{2}$ \\
\hline GásSulfídrico & $0-1$ & $\mathrm{H}_{2} \mathrm{~S}$ \\
\hline
\end{tabular}

O metano do gás natural está presente também nos resíduos sólidos produzidos pela população humana, resíduos esses que vêm aumentando a cada dia devido ao aumento da população. Os resíduos que são gerados pela população são levados aos aterros sanitários onde sofrem o processo de digestão anaeróbia que, por sua vez, leva a formação do biogás que é um gás com considerável teor de metano e gás carbônico além alguns outros componentes em menor porcentagem. A presença de metano em quantidades consideráveis no biogás solicita um cuidado especial dentro dos aterros sanitários no descarte do mesmo. Devido à necessidade desse cuidado especial, ele é queimado após seguir um caminho até a superfície do aterro [4]. O alto teor de metano existente nesse gás fez com que estudos fossem (e ainda são) realizados para verificação da possibilidade de transporte esse gás gerado para ser utilizado com fonte de energia.

Outra grande fonte de emissão de GHG é a pecuária devido à grande quantidade de resíduos sólidos produzidos pelas criações bovina e suína. Os dejetos desses animais com a ajuda da fermentação (digestão anaeróbia) em biodigestores produzem o biogás. Os ruminantes produzem entre 80 e 103 milhões de toneladas de $\mathrm{CH}_{4}$ por ano, totalizando $1 / 4$ da quantidade de metano produzido no mundo [6]. Dados estatísticos mostram que no Brasil a população de ruminantes cresceu $1,6 \%$ em 2011 em comparação com o ano anterior. Isso mostra que o Brasil é uma grande fonte de metano graças a enorme e crescente quantidade de ruminantes que existem em nosso território [7].

Levando em consideração a alta população de ruminantes em território nacional produzindo uma grande quantidade de resíduos sólidos e também considerando a produção de resíduos pelo homem, têm-se fontes valiosas de biogás para ser utilizados em substituição ou em conjunto com o gás natural devido à sua composição similar com a composição do gás natural. Como se trata de um gás, o biogás pode ser transportado pelos mesmos meios que são utilizados pelo gás natural reduzindo custos com logística.

Além de gerar renda em fazendas onde os resíduos produzidos pelas criações eram somente utilizados como adubo, é possível gerar energia o que pode reduzir o consumo de energia elétrica nas fazendas. No caso dos resíduos produzidos pelo homem, principalmente, nas cidades, é possível reduzir a quantidade desses resíduos reduzindo a emissão do gás metano direto na atmosfera. 


\section{MATERIAIS E MÉTODOS}

A simulações feitas nesse trabalho foram feitas com a ajuda de dois programas chamados AFA_1 e AFB_1 pertencentes ao Departamento de Engenharia Metalúrgica e de Materiais da Universidade Federal de Ouro Preto. As composições que foram utilizadas para simulação de composição dos gases provenientes da biodigestão de dejetos suínos, bovinos e de lixo orgânico foram retiradas da literatura.

O primeiro programa reproduz simulação de balanço de massa enquanto o segundo realiza simulação de balanço térmico, ambos em linguage Fortran baseando-se no modelo criado no IRSiD (Institut de Recherche de la Sidérurgie) hoje ArcelorMittal de Lorraine, no Nordeste da França.

As simulações realizadas foram feitas com injeção de gás natural e/ou biogás juntamente com a injeção de carvão pulverizado tendo todos esse materiais composições utilizadas em grandes siderúrgicas do território nacional.

Utilizando o AFB_1 foi posssível realizar o cálculo térmico global de um Alto-Forno tendo como variáveis:

- $\% \mathrm{H}_{2}$ no gás de topo seco e vazão de ar;

- \% da razão $\mathrm{CO} / \mathrm{CO}_{2}$ no topo e vazão de ar;

- $\% \mathrm{H}_{2}$ no gás de topo seco e razão $\mathrm{CO} / \mathrm{CO}_{2}$;

- $\% \mathrm{~N}_{2}$ no gás de topo seco e vazão de ar.

A massa e composição de carvão mineral injetado, coque, minério, sínter, pó de alto-forno, materiais voláteis do coque são determinadas previamente, pois esses são dados de entrada do programa. Além disso, os dados de entrada devem ser padrão, pois, obviamente, a variação deles leva a erros nos resultados encontrados, impossibilitando uma análise comparativa dos resultados.

Coque, carvão mineral e pós de alto-forno tiveram suas composições fornecidas de uma usina integrada a coque e os dados de minério de ferro e sínter são provenientes da própria usina siderúrgica. A matéria prima que é adicionada no topo do forno é composta de coque, minério, com a adição de pelota e sínter, completando assim o balanço de massa do ferro que será, em sua maioria, incorporado no gusa. $\mathrm{Na}$ simulação, com os valores das porcentagens de cada matéria prima em mãos foi possível realizar os cálculos relacionados ao balanço de massa de ferro no reator. Esses valores de porcentagens, a princípio são fixos para qualquer simulação e à medida que iterações ocorrem são feitos ajustes nas composições de todas as matérias primas com o objetivo de atender às especificações pré-determinadas

Durante a simulação os dados são adicionados de acordo com a solicitação do programa, então é feito o cálculo da perda térmica global desejada. Esse valor por sua vez serve de dado de entrada no programa AFA_1 levando assim ao cálculo da quantidade de biogás a ser injetado para que as condições de operação do AF fiquem próximas das condições de operação com o uso de gás natural.

Além das perdas térmicas, o programa AFA_1 utiliza o desvio de Rist e a diferença de temperatura da carga e dos gases no PINCH POINT como dados de entrada e calcula a temperatura dos gases de topo, a partir de dados de operação como leito de fusão, porcentagem de $\mathrm{H}_{2}$ no gás de topo e perdas térmicas (calculadas no AFB_1). Considerou-se que $85 \%$ das perdas térmicas ocorrem na zona de 
elaboração e $15 \%$ na zona de preparação. As outras entradas são semelhantes às entradas utilizadas no programa AFB_1.

Os programas possuem algumas restrições, uma vez que não consideram fatores como a distribuição e permeabilidade da carga, a velocidade de produção e a profundidade do sopro.

Foram realizados os seguintes balanços:

1. $100 \%$ Injeção de gás natural;

2. $75 \%$ Injeção de gás natural e $25 \%$ de Injeção de Biogás;

3. $50 \%$ Injeção de gás natural e $50 \%$ de Injeção de Biogás;

4. $25 \%$ Injeção de gás natural e $75 \%$ de Injeção de Biogás;

5. $100 \%$ de Injeção de Biogás.

Utilizou-se uma taxa de injeção de gases de $100 \mathrm{Nm}^{3} / \mathrm{t}$. Assim, os testes foram realizados com injeções de biogás e gás natural variando em proporções de $0-100 \%$ em quantidade injetada de volume de gás.

A taxa de injeção de carvão pulverizado (150 kg/t) e todos os outros parâmentros foram considerados os mesmos em todos os balanços, variando apenas as taxas de injeção de gás natural e biogás. A temperatura de injeção do biogás, do gás natural e do carvão mineral foi $25^{\circ} \mathrm{C} .0$ carregamento do alto-forno foi contínuo e com aproximadamente $50 \%$ pelota, $30 \%$ de sínter e $20 \%$ de minério.

No que se diz respeito à injeção de gases, o programa oferece apenas as opções de gás natural e gás de coqueria. Assim, alterou-se a composição do gás de coqueria para cada composição de biogás, e as suas entalpias foram consideradas as mesmas. A composição do gás natural usada foi $100 \%$ de $\mathrm{CH}_{4}$ para melhor viabilidade de estudo e foi considerado um volume de biogás com uma taxa de $60 \%$ de $\mathrm{CH}_{4}$ e $40 \%$ de $\mathrm{CO}_{2}$, que é a proporção mais frequente desse gás.

\section{RESULTADOS E DISCUSSÃO}

Através dos estudos, observou-se que o teor de enxofre presente no biogás é muito pequeno, na ordem de poucos ppm's. Além disso, existem novas tecnologias de limpeza e purificação de gases disponíveis e com preços bem acessíveis no mercado. Assim, no que diz respeito ao efeito da injeção de biogás na qualidade do gusa, não é necessário preocupar-se com a contaminação significativa do produto por enxofre.

Após a realização dos testes foi observado que quanto maior a injeção de biogás na composição da mistura do gás injetado, maior será o declínio da temperatura de chama. Assim, após a substituição completa de gás natural por biogás, por exemplo, haverá um declive significativo na temperatura de chama. Isso se deve ao fato de que $\mathrm{o} \mathrm{CO}_{2}$ presente no biogás ter o efeito endotérmico, devido à reação de Boudouard, ou seja, a presença de $\mathrm{CO}_{2}$ implica que haverá a transformação a $\mathrm{CO}$, gerando uma perda de energia na zona de combustão

As Tabelas 4 e 5 mostram os resultados feitos nos programas de simulação em duas etapas. A Tabela 2 consiste na injeção de biogás no alto-forno sem temperatura de chama fixa, ou seja, foi feita a simulação computacional livremente, para se obterem os resultados provocados pela injeção. Verificados os resultados da primeira etapa, onde ocorreu uma baixa temperatura de chama no processo, fixouse a temperatura de chama em torno de $2250^{\circ} \mathrm{C}$ com o auxílio da injeção de oxigênio, e assim se obtiveram coke-rates mais elevadas, conforme a Tabela 3. 
Tabela 2. Relação Temperatura de Chama e Coke-Rate sem Temperatura de chama fixa

\begin{tabular}{ccc}
\hline Injeção & CR (kg/t) & TC $\left({ }^{\circ} \mathbf{C}\right)$ \\
\hline $100 \%$ NG & 383,6 & 1907,0 \\
$75 \%$ NG 25\% BG & 387,0 & 1896,3 \\
$50 \%$ NG 50\% BG & 390,5 & 1885,0 \\
25\% NG 75\% BG & 393,9 & 1862,5 \\
100\% BG & 397,4 & 1843,9 \\
\hline \hline
\end{tabular}

Tabela 3: Relação Temperatura de Chama e Coke-Rate com temperatura de chama fixa

\begin{tabular}{ccc}
\hline Injeção & CR (kg/t) & TC $\left({ }^{\circ} \mathbf{C}\right)$ \\
\hline $100 \%$ NG & 274,7 & 2251,7 \\
$75 \%$ NG 25\% BG & 285,2 & 2250,0 \\
$50 \%$ NG 50\% BG & 291,7 & 2249,1 \\
$25 \%$ NG 75\% BG & 295,1 & 2250,0 \\
$100 \%$ BG & 298,6 & 2250,1 \\
\hline \hline
\end{tabular}

Para o cálculo da temperatura de chama, utilizou-se a Equação (1):

$\mathrm{T}_{\text {chama }}=1267,9+0,9742 \mathrm{~T}_{\mathrm{s}}+57,64 \mathrm{E}-7,146 \mathrm{U}-2 \mathrm{~T}_{\text {ICP }}-4 \mathrm{~V}_{\mathrm{GN}}$

Onde as variáveis utilizadas na simulação foram:

$\mathrm{T}_{\mathrm{S}}=$ temperatura de sopro do $\operatorname{ar}\left(1200^{\circ} \mathrm{C}\right)$

$E=$ enriquecimento do ar em oxigênio ( aproximadamente 2\%)

$\mathrm{U}=$ umidade do $\operatorname{ar}\left(18 \mathrm{~g} / \mathrm{Nm}^{3}\right)$

$T_{P C l}=$ taxa de injeção de carvão (150 kg/t gusa)

$V_{G N}=$ volume de gás natural injetado $\left(100 \mathrm{Nm}^{3} / \mathrm{t}\right.$ gusa $)$

O consumo de redutor variou nos testes, mostrando que a substituição de gás natural por biogás provoca uma variação no consumo teórico de coque e na temperatura de chama. A escolha da temperatura de chama fixa $2250^{\circ} \mathrm{C}$, condiz com as temperaturas de chama reais encontradas nos altos-fornos a coque. Adotou-se a tática de enriquecimento do ar em oxigênio para manter os níveis térmicos na zona de combustão.

\section{CONCLUSÃO}

Conforme resultados apresentados, ou uma queda significativa de temperatura de chama e para solucionar o problema de redução da eficiência térmica de projeto é necessário aumentar o aporte térmico através enriquecimento do ar com oxigênio ou adicionando mais carbono no reator. Porém é preciso estar atento aos efeitos dessas alterações do rendimento do forno e vários parâmetros operacionais, para não prejudicar o funcionamento do Alto-Forno.

A injeção de gases no Alto-forno causa uma maior redução na temperatura adiabática de chama por unidade, se comparado à injeção de carvão, que permite taxas de injeção mais altas e consequentemente, coke-rates mais próximas às condições de idealidade. 


\section{Agradecimentos}

Os autores agradem ao prof. Carlos Antônio da Silva e Itavahn Alves da Silva pela cessão e apoio no uso do modelo matemático, ao CNPq, a CAPES, a Gerdau, a UFOP e a REDEMAT pelo apoio.

\section{REFERÊNCIAS}

1 ABM - $41^{\circ}$ Seminário de Redução de Minério de Ferro e Matérias-Primas. Artigo p. 758769. Vila Velha, ES. 2011.

2 Silva, C.A.; Silva, I.A. Um panorama macroscópico e microscópico de um Alto-forno. p.12. Ouro Preto, 2009.

3 Gasmig, http://www.gasmig.com.br/Gas/Composicao.aspx. Site Visitado em 13 de abril 2015 às 23:35.

4 Bernt, A. Impacto da Pecuária de Corte Brasileira Sobre os Gases do Efeito Estufa. 147 p. Instituto de Zootecnia / APTA III Simpósio Internacional de Produção de Gado de Corte. Nova Odessa, SP. 2010.

5 S. E. Hosseini, M.A. Wahid, Developmentofbiogascombustion in combinedheatandpowergeneration, Elsevier, Volume 40, December 2014, Pages 868 875, 2014.

6 Howden, S.M.; Reyenga, P.J. Methane emissions from Australia livestock: implications of Kyoto Protocol. AustralianJournalofAgriculturalResearch, v.50, p.1285-1291, 1999.

7 IBGE - Instituto Brasileiro de Geografia e Estatística. PPM 2011: cattle herd size rises $1,6 \%$ and reaches 212,8 million head. Out. 2012. Disponível em:

$<$ http://saladeimprensa.ibge.gov.br/en/noticias?view=noticia\&id=1\&busca=1\&idnoticia=22 41> Acesso em: 1 de abr. 2013. 